\title{
CURRENT CONCEPTS ON SPINAL TUBERCULOSIS
}

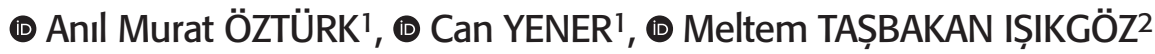 \\ ${ }^{1}$ Ege University Faculty of Medicine, Department of Orthopedics and Traumatology, Izmir, Turkey \\ ${ }^{2}$ Ege University Faculty of Medicine, Department of Clinical Microbiology and Infectious Diseases, Izmir, Turkey
}

Spinal tuberculosis (TB) is seen in $2 \%$ of TB patients and $50 \%$ of skeletal involvement of TB. Low back pain, fever, weight loss, and night sweats are the most common symptoms. However, the gold standard for its diagnosis is the growth of Mycobacterium tuberculosis in culture taken from tissue samples. Magnetic resonance imaging is the preferred imaging modality in the diagnosis of spinal TB. Typical findings include lesions in the vertebral endplates, anterior involvement of the vertebral body, and subligamentous spread. The aim of the treatment is to confirm the diagnosis, to clear the lesion from bacteria, and to eliminate spinal deformity and spinal cord pressure. Drug therapy is recommended for $9-12$ months. There is controversy in the literature regarding the need for additional surgical intervention in the treatment of spinal TB. Many authors have suggested surgery in the presence of progressive neurological deficit, instability, progressive kyphosis above the 50 degrees or disease unresponsive to drug therapy. Surgical approach in spinal TB surgery is still being discussed. The location of the lesion, instability, patient-related factors, and severity of deformity should be considered when deciding on the approach.

Keywords: Spinal, tuberculosis, Pott disease, treatment, surgery

\section{INTRODUCTION}

Spinal tuberculosis (TB) is seen in $2 \%$ of TB patients and $50 \%$ of skeletal involvement of $\mathrm{TB}^{(1)}$. Approximately $90 \%$ of the patients are affected by the lower thoracic and upper lumbar vertebrae ${ }^{(2)}$. Spinal TB can lead to the destruction of the vertebral body, posterior elements and pars interarticularis, which can lead to deformity, spondylolisthesis, and even paraplegia(3). Although clinical examination, patient history and radiography are usually sufficient for diagnosis, early computer tomography and magnetic resonance imaging (MRI) are useful(4,5). Usually, only anti-TB drugs are used in the treatment but surgery may be necessary if signs of spinal compression and neurological deficits, instability, advanced kyphosis deformity or drug resistance occur ${ }^{(6)}$. Debridement, grafting and internal fixation are the main objectives of surgery. Surgical timing, amount of debridement and surgical approach are still controversial( ${ }^{(7)}$. The purpose of this review is to provide information about the current approaches in the diagnosis and treatment of spinal TB.

\section{Diagnosis}

Diagnosis is difficult in the initial stages, delay in diagnosis may lead to serious spinal cord injuries ${ }^{(8)}$. Predisposing factors include malnutrition, alcoholism, diabetes, and human immunodeficiency virus (HIV) infection ${ }^{(9)}$. Symptoms are usually insidious, there may be complaints that have been going on for years before diagnosis ${ }^{(1)}$. Low back pain, fever, weight loss, and night sweats are the most common symptoms ${ }^{(10)}$. The diagnosis usually can be made on the basis of predisposing factors, history of TB disease, clinical findings and imaging methods ${ }^{(1)}$. However, the gold standard in diagnosis is positive Mycobacterium tuberculosis tissue culture ${ }^{(11)}$. Because of this, in the case of clinical suspicion, tissue culture should be performed. In addition, performing polymerase chain reaction in samples taken with biopsy, erythrocyte sedimentation rate (ESR), immunological hematological tests and skin test are helpful in diagnosis ${ }^{(12)}$. Radiography is preferred as the initial imaging method and the "bird's nest" appearance can be seen, evocative of an aortic aneurysmal phenomenon reflected from aortic pulsations ${ }^{(8)}$. Computed tomography (CT) can provide information on the extent of vertebral involvement. Abscess and intra-canal compression can be seen in the CT taken with intrathecal contrast ${ }^{(13)}$. The preferred imaging method for spinal cord TB is MRI. Typical findings include lesions in the vertebral end plates, anterior involvement in the vertebral body, subligamentous spreading, paraspinal cold (without signs of severe acute inflammation) abscesses and calcifications, vertebral bodies, vertebral body destruction and collapse but the disc is usually protected ${ }^{(8)}$. MRI findings can also be used in treatment follow-up, but pain reduction and neurological recovery are more important in follow-up treatment ${ }^{(14)}$. Javed et al. ${ }^{(15)}$ compared the clinical and laboratory findings of patients

Address for Correspondence: Anıl Murat Öztürk, Ege University Faculty of Medicine, Department of Orthopedics and Traumatology, İmir, Turkey E-mail: amuratozturk@yahoo.com Received: 23.01.2020 Accepted: 01.02.2020 ORCID ID: orcid.org/0000-0001-8674-8877 
with spinal epidural tumors and patients with spinal TB. They reported pain, fever, progressive lower extremity weakness, high ESR, epidural and paravertebral contrast involvement, spinal deformity and adjacent level involvement in MRI as possible diagnostic criteria for the spinal tuberculosis. In distinguishing pyogenic spinal infections, laboratory findings and imaging methods are useful. It has been reported that positron emission tomography, the use of which has increased in recent years, can be used in diagnosis and follow-up in pott disease ${ }^{(16)}$.

Interferon gamma release tests used in the diagnosis of latent tuberculosis infection are not reliable in the diagnosis of spinal $\mathrm{TB}^{(17)}$. More clinical trials investigating different antigens are needed in this regard. In addition, although the low sensitivity of nucleic acid amplification methods prevents excluding the diagnosis, it is useful to confirm the diagnosis ${ }^{(18)}$.

Biopsy can be attempted from the suspicious lesion by interventional diagnostic methods or endoscopic methods, but false negative results may be seen in these diagnostic methods ${ }^{(14)}$. Therefore, in the presence of clinical symptoms, the negative interventional diagnostic methods should not prevent open biopsy from being made ${ }^{(19)}$.

\section{Classification}

Based on the clinicopathological correlation, anterior spinal tuberculosis is divided into five stages ${ }^{(20)}$ (Table 1). The stages of anterior spinal tuberculosis differ from their degree of paraplegia. Stages of anterior spinal tuberculosis show bone involvement and degree of deformity while paraplegia degrees indicate the severity of spinal cord compression. Several classifications have been developed for paraplegia grading due to spinal tuberculosis. These were developed to determine the degree of pressure in the spinal cord and to evaluate the severity of the disease in making the surgical decision ${ }^{(21,22)}$. The most common of these is the classification developed by Kumar ${ }^{(22)}$ based on the patient's weakness complaints, walking ability and neurological examination findings (Table 2). There are also classifications that define the paraplegia that occurs within 2 years from the onset of the disease as early onset and the result of active disease, the paraplegia that occurs after 2 years as late onset and the result of sequelae of the disease ${ }^{(23)}$. In both anterior and posterior spinal tuberculosis, motor nerves are affected before the sensory nerves ${ }^{(23,24)}$. Sensory and autonomic loss of function are added as compression increases.

Table 1. Stages of tuberculosis of spine ${ }^{(17)}$

\begin{tabular}{|c|c|c|c|}
\hline Stage & Description & Clinicoradiological features & Usual duration \\
\hline I & $\begin{array}{l}\text { Stage of implantation, } \\
\text { incipient stage or } \\
\text { predestructive stage }\end{array}$ & $\begin{array}{l}\text { Dull back pain with muscle spasm in the back. Straightening of } \\
\text { the spine or loss of curve }\end{array}$ & $<3$ months \\
\hline II & Stage of early destruction & Diminished disk space, paradiskal erosion, kyphosis $<10^{\circ}(\mathrm{K} 1)$ & 2-4 months \\
\hline III & $\begin{array}{l}\text { Stage of advanced destruction and } \\
\text { collapse }\end{array}$ & $\begin{array}{l}\text { Two or more vertebral involvement with collapse. Kyphosis } 11^{\circ} \\
-60^{\circ}(\mathrm{K} 2) \text { or gibbus }>60^{\circ}(\mathrm{K} 3)\end{array}$ & 3-9 months \\
\hline IV & Stage of neurological involvement & Stage III or IV with four grades of paraplegia & Variable \\
\hline $\mathbf{v}$ & $\begin{array}{l}\text { Stage of residual deformity and } \\
\text { aftermath }\end{array}$ & $\begin{array}{l}\text { Kyphosis } \mathrm{K} 1, \mathrm{~K} 2 \text {, K3, disease active locally grumbling, } \\
\text { reactivated or healed }\end{array}$ & $>3-5$ years \\
\hline
\end{tabular}

Table 2. Classification of paraplegia in tuberculosis of spine ${ }^{(19)}$

\begin{tabular}{|c|c|c|c|c|c|}
\hline \multirow{2}{*}{$\begin{array}{l}\text { Grade of } \\
\text { paraplegia }\end{array}$} & \multicolumn{2}{|c|}{ Complaints/symptoms } & \multicolumn{3}{|c|}{ Examination/neurological deficit } \\
\hline & Weakness & Walking & Motor & Sensory & Autonomic \\
\hline 1. & $\begin{array}{l}\text { Negligible or } \\
\text { weakness appearing } \\
\text { after exercise }\end{array}$ & $\begin{array}{l}\text { Able to walk without } \\
\text { support }\end{array}$ & $\begin{array}{l}\text { Extensor plantar } \pm \text { brisk } \\
\text { ankle jerks, muscle power } \\
\text { grade IV to V }\end{array}$ & Nil & Nil \\
\hline 2. & $\begin{array}{l}\text { Mild or Feels } \\
\text { weakness }\end{array}$ & $\begin{array}{l}\text { Able to walk with } \\
\text { support }\end{array}$ & $\begin{array}{l}\text { Motor weakness, brisk } \\
\text { tendon jerks, ill sustained } \\
\text { muscle clonus, muscle } \\
\text { power grade III }\end{array}$ & $\begin{array}{l}\text { Sensory } \\
\text { dulling or } \\
\text { paresthesia }\end{array}$ & Nil \\
\hline 3. & $\begin{array}{l}\text { Moderate or } \\
\text { weakness is more } \\
\text { marked }\end{array}$ & $\begin{array}{l}\text { Not able to walk } \\
\text { Confined to bed } \\
\text { Can move limbs }\end{array}$ & $\begin{array}{l}\text { Brisk tendon jerks, sustained } \\
\text { muscle clonus, muscle } \\
\text { power grade I to II }\end{array}$ & $\begin{array}{l}\text { Hypoesthetic } \\
\text { or anesthetic } \\
\text { patches }\end{array}$ & May be present \\
\hline \multirow{2}{*}{4.} & \multirow{2}{*}{$\begin{array}{l}\text { Severe or Complete } \\
\text { loss of power and } \\
\text { control }\end{array}$} & \multirow{2}{*}{$\begin{array}{l}\text { Not able to move the } \\
\text { limbs even in the } \\
\text { bed }\end{array}$} & $\begin{array}{l}\text { Paraplegia in extension, } \\
\text { power grade } 0\end{array}$ & \multirow{2}{*}{ Total loss } & \multirow{2}{*}{$\begin{array}{l}\text { Complete loss of } \\
\text { bladder } \\
\text { and bowel } \\
\text { control and } \\
\text { incontinence }\end{array}$} \\
\hline & & & $\begin{array}{l}\text { Paraplegia in flexion, power } \\
\text { grade } 0 \text {, flaccid paralysis }\end{array}$ & & \\
\hline
\end{tabular}




\section{Treatment}

The aim of the treatment is to confirm the diagnosis, to clear the lesion from the bacteria, and to eliminate spinal deformity and spinal cord pressure. Rifampicin, isoniazid (INH), pyrazinamide and ethambutol form the basis of drug therapy as anti-TB drugs. British Medical Research Council(25) recommends combination chemotherapy for 6-9 months in the treatment of tuberculous spondylitis of the thoracolumbar spine. However, the work of this council does not include patients with vertebral involvement, cervical lesions, or patients with major neurological involvement. For this reason, many experts still recommend treatment for 9-12 months.

HIV increases the reactivation of the disease, the risk of more atypical and severe course. Studies on spinal tuberculosis and HIV show that good clinical outcomes can occur, regardless of HIV activation status and the presence of antiretroviral therapy ${ }^{(26)}$.

Treatment of spinal tuberculosis with multidrug-resistant microorganism (resistant to INH and rifampicin) or extensively drug-resistant microorganism [(resistant to a quinolone and a parenteral drug (amikacin, kanamycin or capreomycin) with $\mathrm{INH}$ and rifampicin)] should continue in specialized centers experienced in management.

In the literature, controversy continues regarding the need for additional surgical intervention in the treatment of spinal TB. Jutte and Van Loenhout-Rooyackers ${ }^{(27)}$, in their review with randomized controlled trials, compared spinal tuberculosis cases treated with chemotherapy only with those who received surgical treatment in addition to chemotherapy. In this study, deterioration in kyphosis angle, neurological deficit, bone fusion, recovery from disease and activity recovery rates at baseline or follow-up were evaluated, but no significant difference was found between these two groups in terms of these results. Nevertheless, many authors have proposed surgery in the presence of progressive neurological deficit, instability, progressive kyphosis above 50 degrees or disease unresponsive to drug treatment.

In surgery, after debridement, the correction of deformity for decompression and instrumentation can be performed for stabilization. It has been reported that grafting is effective for providing spinal fusion ${ }^{(28)}$. Emergency decompression surgery is indicated only in patients with acute spinal cord compression findings ${ }^{(29)}$.

In some patient groups, there are also studies reporting that only instrumentation can be beneficial without radical debridement. Qian et al.(7), in the study on 74 patients with Frankel et al.(30) grading scores of $D$ and $E$, compared the group with radical debridement, grafting and anterior instrumentation and group with posterior instrumentation only. In terms of operation time, blood loss, and $3^{\text {rd }}$ and $6^{\text {th }}$ month ESR, they found that only posterior instrumentation group had significantly better results, but could not find a significant difference in terms of kyphosis angles or fusion rates.
The surgical approach in spinal tuberculosis surgery is still under discussion. Although the anterior approach provides a larger surgical site and direct access to the lesion, it may create instability after decompression ${ }^{(31)}$. In addition, the use of the posterior approach increases due to the risk of vascular nerve damage, increased blood loss, prolonged operation time and length of hospital stay with the anterior approach ${ }^{(32,33)}$. However, when deciding on the approach, the region of the lesion, instability, patient-related factors and severity of deformity should be taken into account. In spinal tuberculosis with wide anterior destruction, where anterior stability is lost, only the posterior approach may result in poor decompression, poor correction and implant failure ${ }^{(34)}$.

Spinal TB surgery should be performed by experienced surgeons in experienced centers. Among the effective techniques, choosing the technique that is the safest and well known by the surgeon will reduce the complication rates. Moon et. al. ${ }^{(35)}$, in their study on 901 patients who underwent spinal tuberculosis surgery, reported increasing of the corrected kyphosis angle (32\%) and graft failure (14\%) as the most common complications associated with the disease. In the same study, thoracic cavity complications (43\%), thrombophlebitis (26\%) and sympatheticolysis symptoms (32\%) were reported as surgical complications, especially in the anterior approach.

\section{CONCLUSION}

As a result, spinal tuberculosis is still an important disease and should be considered in differential diagnosis in patients with chronic low back pain and neurological symptoms. Imaging tests such as MRI and CT can help to diagnose the disease, but microbiological diagnosis is also required to confirm the diagnosis. Although the main treatment is drug therapy, it is useful to add surgical treatment in case of advanced deformity and paraplegia.

\section{Authorship Contributions}

Surgical and Medical Practices: A.M.Ö., M.I.T., Concept: M.I.T., A.M.Ö., Design: M.I.T.,AM.Ö., Data Collection or Processing: M.I.T., AM.Ö., C.Y., Analysis or Interpretation: M.I.T., AM.Ö., C.Y., Literature Search: C.Y., M.I.T., A.M.Ö., Writing: C.Y., M.I.T., A.M.Ö.

Conflict of Interest: There are no conflicts of interest in connection with this paper, and the material described is not under publication or consideration for publication elsewhere.

Financial Disclosure: The authors declared that there is no financial relationship with this paper.

\section{REFERENCES}

1. Ansari S, Amanullah MF, Ahmad K, Rauniyar R. Pott's spine: Diagnostic imaging modalities and technology advancements. N Am J Med Sci. 2013;5:404-11.

2. Wang H, Li C, Wang J, Zhang Z, Zhou Y. Characteristics of patients with spinal tuberculosis: seven-year experience of a teaching hospital in Southwest China. Int Orthop. 2012;36:1429-34.

3. Moon MS. Tuberculosis of spine: current views in diagnosis and management. Asian Spine J. 2014;8:97-111. 
4. Hoffman EB, Crosier JH, Cremin BJ. Imaging in children with spinal tuberculosis. A comparison of radiography, computed tomography and magnetic resonance imaging. J Bone Joint Surg Br. 1993; 75:233-9.

5. Desai SS. Early diagnosis of spinal tuberculosis by MRI. J Bone Joint Surg Br. 1994;76:863-9.

6. Zou MX, Li J, Lv GH, Wang B, Deng YW. Treatment of thoracic or lumbar spinal tuberculosis complicated by resultant listhesis at the involved segment. Clin Neurol Neurosurg. 2014;125:1-8.

7. Qian J, Rijiepu A, Zhu B, Tian D, Chen L, Jing J. Outcomes of radical debridement versus no debridement for the treatment of thoracic and lumbar spinal tuberculosis. Int Orthop. 2016;40:2081-8.

8. Alvi A, Raees A, Rehmani MAK, et al. Magnetic Resonance Image findings of Spinal Tuberclosis at first presentation. Int Arch Med. 2014;7:12.

9. McLain RF, Isada C. Spinal tuberculosis deserves a place on the radar screen. Cleve Clin J Med. 2004;71:543-9.

10. Chen $\mathrm{CH}$, Chen YM, Lee CW, Chang YJ, Cheng CY, Hung JK. Early diagnosis of spinal tuberculosis. I Formos Med Assoc. 2016;115:825-36.

11. Schirmer P, Renault CA, Holodniy M. Is spinal tuberculosis contagious? Int J Infect Dis. 2010;14:e659-66.

12. Alli OAT, Ogbolu OD, Alaka OO. Direct molecular detection of Mycobacterium tuberculosis complex from clinical samples - An adjunct to cultural method of laboratory diagnosis of tuberculosis. $\mathrm{N}$ Am J Med Sci. 2011;3:281-8.

13. An HS, Seldomridge JA. Spinal infections: Diagnostic tests and imaging studies. In: Clinical Orthopaedics and Related Research. Lippincott Williams and Wilkins; 2006. bl 27-33.

14. Wolinsky E. Tuberculosis. In: Goldman L., Bennett JC (Eds.). Cecil's Textbook of Medicine. 21st Edition, WB Saunders Company, Philadelpia 2211; pp:1620-30.

15. Javed G, Laghari AA, Ahmed SI, Madhani S, Shah AA, Najamuddin F, et al. Development of Criteria Highly Suggestive of Spinal Tuberculosis. World Neurosurg. 2018;116:e1002-6.

16. Schmitz A, Kalicke T, Willkomm P, Grunwald F, Kandyba J, Schimitt O. Use fluorine-18 flouro- 2 - deoxy- D-glucose positron emission tomography in assessing the process of tuberculous spondylitis. J Spinal Disord. 2000;13:541-4.

17. Fan L, Chen Z, Hao XH, Hu ZY, Xiao HP. Interferon-gamma release assays for the diagnosis of extrapulmonary tuberculosis: $A$ systematic review and meta-analysis. FEMS Immunol Med Microbiol. 2012;65:456-66.

18. Tortoli E, Russo C, Piersimoni C, Mazzola E, Dal Monte P, Pascarella $M$, et al. Clinical validation of Xpert MTB/RIF for the diagnosis of extrapulmonary tuberculosis. Eur Respir J. 2012;40:442-7.

19. Razak M, Kamari ZH, Roohi S. Spinal infection--an overview and the results of treatment. Med J Malaysia. 2000;55 Suppl C:18-28.

20. Kumar K. Tuberculosis of spine, natural history of disease and its judicious management. J West Pac Orthop Assoc. 1988;25:1-8.
21. S.M.Tuli. Judicious Management Of Tuberculosis Of Bones, Joints And Spine. Vol 19, Indian Journal of Orthopaedics. Medknow Publications; 2019. 147 bl.

22. Kumar K. Grading of Pott's paraplegia. J Neurol Orthop Med Surg. 1991;2:112-5.

23. Jain AK, Kumar J. Tuberculosis of spine: neurological deficit. Eur Spine J. 2013;22(Suppl 4):624-33.

24. Kumar K. A clinical study and classification of posterior spinal tuberculosis. Int Orthop. 1985;9:147-52.

25. The MRCWP on T of, (1986) S. A controlled trial of six-month and nine-month regimens of chemotherapy in patients undergoing radical surgery for tuberculosis of the spine in Hong Kong. Tenth report of the Medical Research Council Working Party on Tuberculosis of the Spine. Tubercle 1986;67(4):243-59.

26. Govender S, Annamalai K, Kumar KP, Govender UG. Spinal tuberculosis in HIV positive and negative patients: immunological response and clinical outcome. Int Orthop 2000;24:163-6.

27. Jutte PC, Van Loenhout-Rooyackers JH. Routine surgery in addition to chemotherapy for treating spinal tuberculosis. Cochrane database Syst Rev. 2006:CD004532.

28. Alam MS, Phan K, Karim R, Jonayed SA, Munir HKM, Chakraborty S, et al. Surgery for spinal tuberculosis: a multi-center experience of 582 cases. J Spine Surg. 2015;1:65.

29. Varatharajah S, Charles YP, Buy X, Walter A, Steib JP. Update on the surgical management of Pott's disease. Vol 100, Orthopaedics and Traumatology: Surgery and Research. Elsevier Masson SAS; 2014. bl 233-9.

30. Frankel HL, Hancock DO, Hyslop G, Melzak J, Michaelis LS, Ungar $\mathrm{GH}$, et al. The value of postural reduction in the initial management of closed injuries of the spine with paraplegia and tetraplegia. Spinal Cord. 1969;7:179-92.

31. Yao R, McLachlin SD, Rasoulinejad P, Gurr KR, Siddiqi F, Dunning CE, et al. Influence of graft size on spinal instability with anterior cervical plate fixation following in vitro flexion-distraction injuries. Spine J. 2016;16:523-9.

32. Wang $X$, Pang $X$, Wu $P$, Luo $C$, Shen $X$. One-stage anterior debridement, bone grafting and posterior instrumentation vs. single posterior debridement, bone grafting, and instrumentation for the treatment of thoracic and lumbar spinal tuberculosis. Eur Spine J 2014;23:830-7.

33. Kulkarni SS, Lowery GL, Ross RE, Ravi Sankar K, Lykomitros V. Arterial complications following anterior lumbar interbody fusion: report of eight cases. Eur Spine J. 2003;12:48-54.

34. Yang P, Zang Q, Kang J, Li H, He X. Comparison of clinical efficacy and safety among three surgical approaches for the treatment of spinal tuberculosis: a meta-analysis. Eur Spine J. 2016;25:3862-74.

35. Moon MS, Kim SS, Moon YW, Moon Hanlim H, Kim SS. Surgeryrelated complications and sequelae in management of tuberculosis of Spine. Asian Spine J. 2014;8:435-45. 